\title{
Are blood vessels a target to treat lower urinary tract dysfunction?
}

\author{
Martin C. Michel ${ }^{1} \cdot$ Russ Chess-Williams ${ }^{2}$ • \\ Sharath S. Hegde ${ }^{3}$
}

Received: 20 May 2015 / Accepted: 21 May 2015 /Published online: 31 May 2015

(C) Springer-Verlag Berlin Heidelberg 2015

\begin{abstract}
Bladder dysfunction is common in the general population (Stewart et al. 2010) and even more so among patients seeing a physician for any reason (Goepel et al. 2002). It often manifests as lower urinary tract symptoms (LUTS), a term originally coined to describe voiding and storage symptoms in men with benign prostatic hyperplasia (BPH) but now more universally used to describe any type of voiding and storage symptoms in both sexes. Studies into possible causes of urinary bladder dysfunction have long focused on detrusor smooth muscle cells (Turner and Brading 1999). More recently, it became clear that several other types of cells and organs contribute to regulating detrusor smooth muscle function. These include the urothelium (Andersson and McCloskey 2014; Michel 2015), afferent nerves (Michel and Igawa 2015; Yoshimura et al. 2014b), and the central and autonomic nervous systems (Fowler and Griffiths 2010; Yoshimura et al. 2014a). Alterations in any of these may at least partly be responsible for detrusor dysfunction and, accordingly, be potential targets for the treatment of bladder dysfunction. As highlighted by an article in this issue of NaunynSchmiedeberg's Archives of Pharmacology (Bayrak et al. 2015), there is an additional suspect, the bladder vasculature. This article will discuss the currently available experimental and clinical evidence for a role of the vasculature in causing
\end{abstract}

Martin C. Michel

marmiche@uni-mainz.de

1 Department of Pharmacology, Johannes Gutenberg Universität, Obere Zahlbacher Str. 67, 55101 Mainz, Germany

2 Centre for Urology Research, Faculty of Health Sciences \& Medicine, Bond University, Queensland, Australia

3 Department of Pharmacology, Theravance Biopharma, South San Francisco, CA, USA bladder dysfunction, and how existing and emerging treatments may modulate bladder function by acting on blood vessels. Due to a similarity in concept, data on prostate perfusion will also be discussed to some extent.

\section{Physiology of bladder perfusion}

The urinary bladder receives its blood supply from a fanlike ramification of the internal iliac artery. This ramification shows sexual dimorphism and is highly inconsistent between individuals. Studies in the general circulation have shown that the specific receptors expressed in vascular smooth muscle and endothelium controlling vascular tone may differ considerably between vascular beds. For instance, among the adrenoceptors, the subtypes of $\alpha_{1-}$ and of $\beta$-adrenoceptors contributing to vasoconstriction and vasodilation, respectively, can differ between specific vessels under investigation and also between species (Guimaraes and Moura 2001). Among the $\alpha_{1}$-adrenoceptors, generally the role of the $\alpha_{1 \mathrm{~A}}$-subtypes tends to be greatest in small vessels (Chen et al. 1996, 1997), whereas other subtypes may play a bigger role in larger vessels (Rudner et al. 1999). However, little information is available on the receptor systems specifically controlling the tone of blood vessels providing perfusion of the bladder. The $\alpha_{1 \mathrm{~A}^{-}}$ adrenoceptors, perhaps in its $\alpha_{1 \mathrm{~L}}$-phenotype, may mediate contraction of small arteries in the porcine prostate (Recio et al. 2008).

Vascular tone depends on the balance between receptors on the vascular smooth muscle cells and those on endothelial cells. For example, vasoconstriction of mouse retinal arterioles in response to phenylephrine only becomes detectable upon endothelial damage (Böhmer et al. 2014), indicating that $\alpha_{1}$-adrenoceptors are expressed in both smooth muscle and endothelium of this vessel where they mediate opposite effects 
on vascular tone. Similarly, B2 bradykinin receptors are largely found in endothelium in large vessels, but mostly in smooth muscle in arterioles including those of the urinary bladder (Figueroa et al. 2001).

Similar to intramural vessels of the heart, the diameter of those in the bladder is regulated passively by the filling state of the organ. Early in the micturition cycle, bladder perfusion can initially increase with bladder filling; however, as the micturition cycle continues, high physiological filling of the bladder can compress the blood vessels in the bladder wall (Goi et al. 2013; Kershen et al. 2002; Nomiya et al. 2012b). The mechanisms regulating bladder perfusion beyond passive vessel compression have not been defined in great detail, but spontaneous contractions of suburothelial venule pericytes have been described (Hashitani et al. 2012). Nitric oxide (NO) appears to cause vasodilatation mainly for mucosal vessels and less so for those of the detrusor (Pontari and Ruggieri 1999).

\section{Effects of short-term hypoperfusion/ischemia of the bladder}

Valid analysis of the relationship between perfusion and function of the bladder requires models in which both can be monitored and manipulated quantitatively and effects of extrinsic variables be minimized. Models allowing this have been reported (Parsons et al. 2012), but not all studies in the field fulfill these criteria. One experimental approach to explore the role of perfusion in the regulation of bladder function is imposing short periods of hypoperfusion or even ischemia. In a setting close to the physiological situation, bladder blood flow can be reduced by short periods of bladder over-distension, which particularly affects submucosal capillaries. Removal of the over-distension only partly restored capillary blood flow; however, a full recovery was observed in rats pre-treated with tamsulosin, providing initial evidence for a role of $\alpha_{1}$ adrenoceptors in the hypoperfusion-induced damage (Mizuno et al. 2010). Along with the only partially restored perfusion, a shortening of micturition intervals was observed, which also was ameliorated by tamsulosin treatment, indicating that hypoperfusion affected bladder function. Of note, tamsulosin did not alter basal bladder blood flow in this model, indicating a lack of tonic activation of the involved $\alpha_{1}$-adrenoceptors in the bladder vasculature in healthy rats (Okutsu et al. 2011).

In other models, acute hypoperfusion is induced by clamping of blood vessels supplying the bladder. Such acute ischemia reduced the contractile bladder response to field stimulation and to a lesser extent to the receptor agonist carbachol or the receptor-independent stimulus $\mathrm{KCl}$, suggesting that both smooth muscle function and neuronal transmitter release were affected (Levin et al. 2000). A similar observation was made upon bladder outlet obstruction (BOO) for 17 days, which reduced bladder contraction in response to field stimulation more than that in response to carbachol, ATP, or $\mathrm{KCl}$; in that model, the difference between response to field stimulation and various agonists was at least partly explained by some degree of denervation (Barendrecht et al. 2007).

\section{Effects of chronic hypoperfusion of the bladder}

While the above data with acute or short-term intervention illustrate the concept that hypoperfusion may impair bladder function, models of chronic hypoperfusion probably have greater pathophysiological relevance. The two main approaches which have been applied are those of artery ligation and those of atherosclerosis. The first approach has shown that the bladder vasculature exhibits some degree of plasticity, i.e., the initial reduction of bladder perfusion after iliac artery ligation partly recovers within 4 weeks (Ishida et al. 1999). However, changes in perfusion have been shown to influence both structure and function in the lower urinary tract, with a recent study using stenosis of the vena cava in rats observing prostatic enlargement, histological signs of $\mathrm{BPH}$, and urodynamic evidence of bladder overactivity after 4-6 weeks of hypoperfusion (Kirpatovskii et al. 2015).

Several atherosclerosis models have been applied in studies of bladder perfusion and function. One model uses rabbits receiving a high-cholesterol diet alone or in combination with balloon injury of the endothelium of the iliac arteries. This model caused a reduced perfusion of the bladder wall and also bladder fibrosis (Azadzoi et al. 1999b). Follow-up work by these investigators leveraged the observation that the degree of atherosclerosis and perfusion impairment differed between individual rabbits. Severe ischemia was associated with impaired bladder contractility in vivo and in vitro, i.e., detrusor underactivity, whereas moderate ischemia was associated with increased contractile bladder responses to carbachol or field stimulation in vitro and increased bladder activity in vivo, i.e., caused detrusor overactivity (Azadzoi et al. 1999a). Detrusor overactivity in this rabbit atherosclerosis model was associated with an enhanced role of afferent nerves (Azadzoi et al. 2008), cyclic ischemia-reperfusion with bladder filling (Azadzoi et al. 2010), and increased expression of hypoxiainducible factor- $1 \alpha$, transforming growth factor- $\beta$, and nerve growth factor (Azadzoi et al. 2011). Moreover, this was accompanied by partial bladder denervation (Azadzoi et al. 2007, 2010, 2011). If partial bladder denervation indeed occurs both with atherosclerosis and with BOO (Barendrecht et al. 2007), the possibility arises that co-existence of these two factors may lead to an exaggerated response.

Several rat models have also been used to explore the effects of atherosclerosis on bladder function, but have been studied in less detail than the rabbit model. Applying the combination of a high-cholesterol diet with balloon injury to the iliac artery in rats confirmed many findings from the rabbit 
model (Nomiya et al. 2012a, 2012b). In those studies, atherosclerosis was reported not only for the iliac arteries abut also for bladder microvessels. Similar to the rabbit model, bladder filling caused greater reductions in blood flow in atherosclerotic than in control rats. Atherosclerosis enhanced the expression of inflammatory cytokines, increased oxidative stress, and functionally led to increased voiding frequency. These investigators also compared the effects of a high-cholesterol diet to rats for 8 weeks combined with either iliac artery balloon injury, treatment with the NO synthase inhibitor $N^{\mathrm{G}}$-nitro-L-arginine methyl ester (L-NAME) or both, to rats receiving none of the three interventions (Nomiya et al. 2014). While L-NAME alone did not change wall thickness of the iliac artery, this was increased by balloon injury and further increased by L-NAME plus balloon injury. All three interventions reduced in vitro contractile bladder responses to carbachol, ATP, and $\mathrm{KCl}$ which consistently were least pronounced with L-NAME and most pronounced with L-NAME plus arterial injury. In vivo, micturition interval, bladder capacity, and voided volume were reduced by either L-NAME or balloon injury but increased by their combination; maximum pressure and bladder compliance were not altered by either treatment, whereas only combination treatment increased residual volume. Collagen content in the bladder muscle layer was increased by balloon injury irrespective of concomitant LNAME treatment.

Finally, some investigators have used a genetically engineered mouse model of atherosclerosis, the apolipoprotein E knock-out mouse. This model did not exhibit alterations of bladder contraction responses in vitro (Shenfeld et al. 2005), but upon concomitant knock-out of the genes for apolipoprotein $\mathrm{E}$ and the low density lipoprotein receptor, detrusor overactivity was observed (Bschleipfer et al. 2015).

BOO, leading to bladder hypertrophy, is a model in which bladder perfusion can be chronically reduced independent of atherosclerosis and may be representative for men with enlarged prostates. In pigs, BOO increased detrusor pressure during voiding and enhanced the associated reductions of blood flow (Greenland and Brading 2001). In rabbits, 2 weeks of BOO caused greater reductions of bladder blood flow and increases of hypoxia than a 2 -h period of ischemia (Lin et al. 2011). The relevance of these findings for patients was indicated by the observation that expression of hypoxia-inducible factor in muscle bundles and submucosa was found in men with prostatic enlargement, presumably causing some degree of BOO, but not in controls (Koritsiadis et al. 2008). An interesting, although not fully conclusive, extension of this concept comes from studies in men with BPH; some of them exhibit persistent detrusor overactivity after prostatectomy, and these had a higher bladder vascular resistance index than those without bladder overactivity (Mitterberger et al. 2007).

The above studies demonstrate that atherosclerosis and other models of bladder hypoperfusion are associated with bladder dysfunction in various animal models. Similarly, the resistive index of capsular arteries of the prostate has been linked to symptoms of bladder outlet obstruction in men with benign prostatic enlargement (Zhang et al. 2012). Bladder hypoperfusion leads to detrusor overactivity in many settings, but severe forms can cause detrusor underactivity

A study in this issue of the journal (Bayrak et al. 2015) expands our knowledge in two ways. Firstly, this study treated rats with a high-cholesterol diet for 4 weeks during which plasma cholesterol doubled but atherosclerosis as assessed by histological examination of the aorta did not yet develop, i.e., the model represented a very early stage in the development of atherosclerosis. Second, they explored effects of this intervention not only on bladder contractility but also on the ability of $\beta$-adrenoceptor agonists to cause detrusor relaxation. In this model of a relatively mild pathology, in vivo bladder function exhibited only minor if any alteration; moreover, frequency and amplitude of spontaneous contractions as well as peak contractile responses to carbachol were not altered in isolated bladder strips. On the other hand, the maximum relaxation responses to isoprenaline were enhanced in both groups of rats in the presence of the $\mathrm{M}_{2}$-preferring antagonist methoctramine, and in the presence of methoctramine isoprenaline caused similar maximum relaxation in both groups. These findings indicate that a relatively short period of hypercholesterolemia may not affect the $\mathrm{M}_{3}$-mediated direct contractile responses to carbachol, but may already enhance the function of relaxation-inhibiting $\mathrm{M}_{2}$ receptors (Witte et al. 2011), thereby indirectly impairing $\beta$-adrenoceptor-mediated detrusor relaxation. As relaxation of rat detrusor is mediated by a combination of $\beta_{2}$ - and $\beta_{3}$-adrenoceptors, which may be regulated differently in the bladder (Michel 2014), the authors also studied relaxation by the $\beta_{2}$-agonist salbutamol and the mildly $\beta_{3}$-selective agonist BRL 37,344 and found that both exhibited slightly enhanced relaxation responses in the presence of methoctramine in rats with hypercholesterolemia in comparison to those without; however, these findings are difficult to interpret as responses to isoprenaline were not enhanced.

\section{Clinical associations between atherosclerosis risk factors and bladder dysfunction}

The above findings in multiple animal models establish that hypoperfusion and resulting hypoxia of the bladder may affect its function. In early and/or mild-to-moderate stages, this may lead to detrusor overactivity and in late and/or severe stages to detrusor underactivity, as specifically shown in atherosclerosis models. This situation is similar to that seen in experimental diabetes where mild forms and/or early stages are associated with overactivity, whereas late stages or severe forms can lead to underactivity (Golbidi and Laher 2010; Michel and 
Barendrecht 2008). Important causes of atherosclerosis in patients include long-standing arterial hypertension, dyslipidemia, and diabetes. While we are not aware of clinical studies directly exploring associations between atherosclerosis and bladder dysfunction or male LUTS, several clinical studies have explored possible associations between atherosclerosis risk factors such as hypertension, hyperlipidemia, metabolic syndrome, and diabetes on the one hand and bladder dysfunction and male LUTS on the other. In this regard, it should be noted that the definition of LUTS in men in most studies did not allow clear discrimination between those associated with $\mathrm{BPH}$ versus those associated with $\mathrm{OAB}$. This is important as the risk factors being associated with LUTS may differ between genders (Coyne et al. 2009).

Studies testing an association of OAB/LUTS with hypertension in a female or mixed gender population have yielded mixed results. Among 1724 men and 812 women participating in a health screening project, the association of LUTS, assessed as International Prostate Symptom Score (IPSS), with the vascular risk factors of hypertension, hyperlipidemia, diabetes, and nicotine use were explored (Ponholzer et al. 2006). Among men, IPSS scores were the same (6.6) for those with no, or just one, risk factor, but increased to 7.7 in those with two or more risk factors; among women, IPSS increased from 4.8 in those with no risk factor to 5.7 and 7.0 in those with one or with two or more risk factors, respectively. We have recently performed a pre-planned secondary analysis of the pre-treatment data of a post-marketing surveillance study of the muscarinic receptor antagonist solifenacin; in this study, including 4450 men and women with OAB symptoms, we did not detect an association of the presence of hypertension with the intensity of OAB symptoms (Ochodnicky and Michel, unpublished observation). Finally, the largest mixed gender study comes from an internet-based survey of about 30,000 participants in the US, UK, and Sweden (EpiLUTS Study) in which the presence of combined voiding, storage, and postmicturition symptoms was associated with several comorbid conditions including hypertension in both genders (Coyne et al. 2009).

Following contradictory reports from several small cohorts, associations between LUTS and hypertension have also been explored in larger groups of men with suspected BPH. In the pre-treatment data of an observational study among 9857 men going to receive tamsulosin treatment, IPSS and presence of hypertension were associated; the IPSS difference attributed to presence of hypertension was quantitatively similar to that of a 12-year age difference with the same dataset (Michel et al. 2004). Similarly, among 2372 men participating in the NHANES III study, a history of hypertension was associated with an odds ratio of 1.76 for the presence of LUTS (Rohrmann et al. 2005). However, such associations were not observed in some other cohorts. Thus, among 1206 mean in the comparison arm of the Air Force Health Study, greater systolic blood pressure was not associated with an increased risk of clinically diagnosed BPH (Gupta et al. 2006). Similarly, among 1103 randomly selected, community-dwelling men from Australia, neither storage nor voiding LUTS were associated with systolic or diastolic blood pressure (Martin et al. 2011). Thus, associations between male LUTS and hypertension were reported inconsistently and hence are inconclusive. However, it is noteworthy that they were found in the larger studies including men with LUTS, but absent in smaller studies not selecting participants for the presence of LUTS. This may point to an association which is not strong enough to be observed unless the cohorts are very large and/or enriched in men with LUTS.

Interestingly, sympathetic nervous system overactivity has been reported in men with LUTS and in a frequently used animal model of hypertension, the spontaneously hypertensive rat (McVary et al. 2005). Spontaneously hypertensive rats also exhibit detrusor overactivity, and the blood pressure and bladder phenotypes of this model co-segregated in crossbreeding studies (Clemow et al. 1999). Both phenotypes may be linked to increased expression of nerve growth factor (Ochodnicky et al. 2011). Moreover, it has been reported that SHR exhibit a lower basal bladder perfusion than normotensive Wistar Kyoto rats, a frequently used control strain in SHR studies; treatment of SHR with doxazosin increased perfusion and expression of NO synthase (which chronically may facilitate perfusion), whereas treatment with nifedipine did not (Yono et al. 2007). The study also showed reduced prostate perfusion in SHR, a finding confirmed in a separate study (Saito et al. 2014). In the latter study, treatment with nicorandil restored prostate perfusion and concomitantly reduced the elevated expression of hypoxia-inducible factor $1 \alpha$, transforming growth factor $\beta 1$, and basic fibroblast growth factor.

Hyperlipidemia, specifically an increased plasma total or LDL cholesterol, is another risk factor for the development of atherosclerosis. A recent systematic review of associations between female LUTS and metabolic syndrome or components thereof identified four studies exploring such associations for hyperlipidemia, of which three found no significant association and one increased odds for OAB in women with hyperlipidemia (Bunn et al. 2015). Among similar studies in men, one comparing 120 men with and 285 without LUTS, total, HDL, and LDL cholesterol as well as triglyceride levels measured after an overnight fast did not differ significantly between groups (Rohrmann et al. 2005). However, among 1103 randomly selected, community-dwelling men from Australia, linear associations between storage LUTS and low HDL cholesterol were observed (Martin et al. 2011). In a follow-up analysis of this cohort, greater HDL cholesterol and lower triglycerides were associated with improvement of storage LUTS, whereas lower HDL cholesterol at baseline was associated with progression of LUTS (Martin et al. 2014). 
Other studies have explored associations between presence and/or intensity of male LUTS and diabetes. Among mixed gender studies, presence of diabetes was associated with extent of LUTS in both genders in the EpiLUTS Study, although it was driven by different symptoms in each gender (Coyne et al. 2009). Among studies in men, several small early studies had yielded inconsistent results (Michel et al. 2000). In probably the largest study which was based on 9856 men with clinically diagnosed BPH, increasing IPSS was associated with a higher odds ratio for having a diagnosis of diabetes; conversely, men with diabetes had a greater IPSS and a smaller maximum urine flow rate (Michel et al. 2000). Among 1103 Australian men, a linear association between storage LUTS and plasma glucose was observed (Martin et al. 2011). Among 1206 participants of the control arm of the Air Force Health Study, a higher fasting blood glucose was associated with a greater risk for a diagnosis of $\mathrm{BPH}$, but the relative risk was close to 1 (1.004; $95 \%$ confidence interval 1.001-1.007) (Gupta et al. 2006). In the NHANES III study, a history of diabetes was associated with a numerically increased odds ratio for LUTS (1.67; $95 \%$ confidence interval $0.72-3.86)$, but no significant associations were seen with increasing glycosylated hemoglobin or fasting 2-h glucose or insulin levels (Rohrmann et al. 2005). Among participants of the Osteoporotic Fractures in Men study, presence of diabetes and quartile distribution of fasting glucose and insulin did not differ between men with and without LUTS ( $n=524$ and 1171, respectively) (Parsons et al. 2011). Among 217 men undergoing prostatectomy, fasting glucose levels were not associated with prostate volume (Gacci et al. 2013). Taken together, these studies do not yield an unequivocal picture, but the weight of the evidence points to an association between diabetes and presence and/or severity of LUTS, particularly male LUTS, but the strength of the association may be too small to allow robust detection. A similar conclusion has recently been reached by other investigators, who also proposed a mechanistic basis for such associations (Breyer and Sarma 2014). Of note, earlier work in experimental animals had also provided evidence for a mechanistic basis for an association between insulin resistance and BPH (Vikram et al. 2010). However, it should be noted that animal studies suggest that detrusor overactivity observed in mild and/or early stages of diabetes may turn into underactivity in late and/or severe forms (Golbidi and Laher 2010). If a similar situation exists in patients, studies not taking duration and severity of diabetes into account may have missed associations due to cases of over- and underactivity at least partial cancelling each other.

Taken together, no fully consistent picture has emerged for associations between risk factors of atherosclerosis (hypertension, dyslipidemia, diabetes) and LUTS. Possible reasons for such inconsistency include small sample sizes, different definitions of bladder dysfunction, and different definitions and assessments of dyslipidemia and diabetes. Moreover, most of the evidence comes from epidemiological studies or case series which did not attempt to measure lower urinary tract perfusion, something that is difficult to do and probably impractical in large studies. Another potential explanation for the inconsistent associations in humans as compared to the compelling evidence from animal studies, particularly in atherosclerosis models, is the direct demonstration of atherosclerosis in the animal models, but only the presence of risk factors for atherosclerosis in the human studies. This problem may be aggravated by the fact that dyslipidemia and diabetes often co-exist as part of the metabolic syndrome. Indeed, some studies in which dyslipidemia and/or diabetes had only small if any effects observed tighter associations and/or greater effect sizes when LUTS were compared to presence of the metabolic syndrome (Gupta et al. 2006; Rohrmann et al. 2005). Associations between intensity of male LUTS and presence of the metabolic syndrome were also observed from the Boston Area Community Health (BACH) Survey (Kupelian et al. 2009). In line with these clinical findings, bladder dysfunction has also been reported in rat models of metabolic syndrome (Chung et al. 2013; Lee et al. 2008). In line with others (Bunn et al. 2015; Kirby et al. 2010), we conclude that metabolic syndrome apparently exhibits a more robust association with LUTS than its individual components of dyslipidemia and diabetes.

\section{Effects of therapeutics on bladder perfusion}

The above studies establish associations between hypoperfusion and bladder dysfunction, specifically of detrusor overactivity in experimental animals. However, perhaps clinically more relevant are two other questions: Do existing effective treatments of OAB and/or male LUTS also affect bladder perfusion? Will drugs targeting bladder and prostate perfusion affect the function of these organs? Until now, only limited evidence is available in this regard.

Indeed, several agents with proven beneficial effects in the treatment of OAB and/or male LUTS have been shown to increase bladder and/or prostate perfusion. For example, in a rat $\mathrm{BOO}$ model, treatment with tamsulosin restored perfusion and increased voided volume (Okutsu et al. 2010). Such findings were confirmed by other investigators using a different experimental approach (Mine et al. 2013). Another $\alpha_{1}$ adrenoceptor antagonist, silodosin, restored bladder perfusion in spontaneously hypertensive rats, which exhibit an OABlike phenotype (Inoue et al. 2012). Silodosin was also reported to improve bladder flow and voiding frequency in a rat atherosclerosis model (Goi et al. 2013). In a series of 30 consecutive men with LUTS and unsatisfied with their symptom improvement during $\alpha$-blocker treatment, a 24-week add-on treatment with dutasteride reduced prostate size, improved LUTS, and reduced the bladder vascular resistive index (Wada et al. 2015). Within this study the 20 men reporting 
persisting urgency, bladder perfusion was improved to a smaller degree than in the 10 without urgency.

A more difficult but potentially more relevant question is whether vasodilators will improve LUTS. The rho-kinase inhibitor Y 27,632 is a known vasodilator, at least in hypertensive animals, and along with a reduction of systemic blood pressure reduced detrusor overactivity in spontaneously hypertensive rats (Rajasekaran et al. 2005); however, this may reflect direct effects of rho-kinase inhibition on detrusor smooth muscle function (Peters et al. 2006). Possibly more interesting are findings with nicorandil, which reduced prostate weight and increased prostate perfusion in SHR in the absence of effects on systemic blood pressure (Saito et al. 2014). Limited clinical data show that a combination of the $\alpha_{1}$-adrenoceptor antagonist terazosin and the $\mathrm{Ca}^{2+}$-entry blocker amlodipine yielded superior blood pressure and LUTS reduction than either monotherapy in a group of 355 men (Liu et al. 2009).

\section{Conclusions}

Recent years have provided sound evidence in experimental animals that chronic reduction of bladder perfusion can cause detrusor overactivity, which when severe and/or long lasting can turn into underactivity. Human data in this regard are less consistent but point in a similar direction. Moreover, at least some drugs effective in LUTS treatment also have been shown to improve bladder perfusion, and vasodilators may beneficially affect bladder and/or prostate function. While these data are promising, a definitive analysis of the role of bladder perfusion in the occurrence and, more importantly, treatment of LUTS will require more studies. Among those, clinical intervention studies are the most needed study type. The apparent holy grail of such studies would be novel therapeutics which improve LUTS by increasing lower urinary tract perfusion without affecting systemic hemodynamics; however, on theoretical grounds, this may be difficult to achieve.

Conflict of interest MCM has received consultancy fees, lecturer honoraria, and/or research support in the OAB and male LUTS field from AltheRX, Astellas, Bayer, and Pfizer. He currently is an employee of Boehringer Ingelheim. RCW has received lecturer honoraria and/or research support in the $\mathrm{OAB} / \mathrm{BOO}$ field from Astellas and Pfizer.SH is an employee of Theravance Biopharma.

\section{References}

Andersson K-E, McCloskey KD (2014) Lamina propria: the functional center of the bladder? Neurourol Urodyn 33(1):9-16

Azadzoi KM, Tarcan T, Kozlowski R, Krane RJ, Siroky MB (1999a) Overactivity and structural changes in the chronically ischemia bladder. J Urol 162(5):1768-1778
Azadzoi KM, Tarcan T, Siroky MB, Krane RJ (1999b) Atherosclerosisinduced chronic ischemia causes bladder fibrosis and noncompliance in the rabbit. J Urol 161(5):1626-1635

Azadzoi KM, Yalla SV, Siroky MB (2007) Oxidative stress and neurodegeneration in the ischemic overactive bladder. J Urol 178(2):710 715

Azadzoi KM, Radisavljevic ZM, Siroky MB (2008) Effects of ischemia on tachykinin-containing nerves and neurokinin receptors in the rabbit bladder. J Urol 71(5):979-983

Azadzoi KM, Radisavljevic ZM, Golabek T, Yalla SV, Siroky MB (2010) Oxidative modification of mitochondrial integrity and nerve fiber density in the ischemic overactive bladder. J Urol 183(1):362-369

Azadzoi KM, Chen BG, Radisavljevic ZM, Siroky MB (2011) Molecular reactions and ultrastructural damage in the chronically ischemic bladder. J Urol 186(5):2115-2122

Barendrecht MM, Chichester P, Michel MC, Levin RM (2007) Effect of short-term outlet obstruction on rat bladder nerve density and contractility. Auto Autacoid Pharmacol 27(1):47-54

Bayrak S, Balkanci ZD, Pehlivangoglu B, Karabulut I, Karaismailoglu S, Erdem A (2015) Does hypercholesterolemia effect the relaxation of the detrusor smooth muscle in rats? In vitro and in vivo studies. Naunyn-Schmiedeberg's Archives Pharmacol

Böhmer T, Manicam C, Steege A, Michel MC, Pfeiffer N, Gericke A (2014) The $\mathrm{a}_{1 \mathrm{~B}}$-adrenoceptor subtype mediates adrenergic vasoconstriction in mouse retinal arterioles with damaged endothelium. Br J Pharmacol 171(16):3858-3867

Breyer BN, Sarma AV (2014) Hyperglycemia and insulin resistance and the risk of BPH/LUTS: an update of recent literature. Curr Urol Rep 15(12):462

Bschleipfer T, Dannenmaier AK, Illig C, Kreisel M, Gattenlöhner S, Langheinrich AC, Krombach GA, Weidner W, Kampschulte M (2015) Systemic atherosclerosis causes detrusor overactivity - functional and morphological changes in hyperlipoproteinemic apoE $\mathrm{E}^{-/-}$, LDLR $^{-/}$mice. J Urol 193(1):345-351

Bunn F, Kirby M, Pinkney E, Cardozo L, Chapple C, Chester K, Cruz F, Haab F, Kelleher C, Milsom I, Sievart KD, Tubaro A, Wagg A (2015) Is there a link between overactive bladder and the metabolic syndrome in women? A systematic review of observational studies. Int J Clin Pract 69(2):199-217

Chen H, Fetscher C, Schäfers RF, Wambach G, Philipp T, Michel MC (1996) Effects of noradrenaline and neuropeptide $Y$ on rat mesenteric microvessel contraction. Naunyn Schmiedeberg's Arch Pharmacol 353:314-323

Chen H, Bischoff A, Schäfers RF, Wambach G, Philipp T, Michel MC (1997) Vasoconstriction of rat renal interlobar arteries by noradrenaline and neuropeptide Y. J Auton Pharmacol 17:137-146

Chung S-D, Chien C-T, Yu H-J (2013) Alterations in peripheral purinergic and muscarinic signaling of rat bladder after long-term fructose-induced metabolic syndrome. Eur J Nutr 52:347-359

Clemow DB, Spitsbergen JM, McCarty R, Steers WD, Tuttle JB (1999) Altered NGF regulation may link a genetic predisposition for hypertension with hyperactive voiding. J Urol 161(4):1372-1377

Coyne KS, Kaplan SA, Chapple CR, Sexton CC, Kopp ZS, Bush EN, Aiyer LP (2009) Risk factors and comorbid conditions associated with lower urinary tract symptoms: EpiLUTS. BJU Int 103(Suppl 3):24-32

Figueroa CD, Marchant A, Novoa U, Förstermann U, Jarnagin K, Schölkens B, Müller-Esterl W (2001) Differential distribution of bradykinin $\mathrm{B} 2$ receptors in the rat and human cardiovascular system. Hypertension 37(1):110-120

Fowler CJ, Griffiths DJ (2010) A decade of functional brain imaging applied to bladder control. Neurourol Urodyn 29(1):49-55

Gacci M, Vignozzi L, Sabstianelli A, Salvi M, Giannessi C, De Nunzio C, Tubaro A, Corona G, Rastrelli G, Santi R, Nesi G, Serni S, Carini M, Maggi M (2013) Metabolic syndrome and lower urinary tract 
symptoms: the role of inflammation. Prostate Cancer Prostatic Dis 16(1):100-105

Goepel M, Hoffmann J, Piro M, Rübben H, Michel MC (2002) Prevalence and physician awareness of symptoms of urinary bladder dysfunction. Eur Urol 41(3):234-239

Goi Y, Tomiyama Y, Nomiya M, Sagawa K, Aikawa K, Yamaguchi O (2013) Effects of silodosin, a selective $\mathrm{a}_{1 \mathrm{~A}}$-adrenoceptor antagonist, on bladder blood flow and bladder function in a rat model of atherosclerosis induced chronic bladder ischemia without bladder obstruction. J Urol 190(3):1116-1122

Golbidi S, Laher I (2010) Bladder dysfunction in diabetes mellitus. Front Pharmacol 1:136

Greenland JE, Brading AF (2001) The effect of bladder outflow obstruction on detrusor blood flow changes during the voiding cycle in conscious pigs. J Urol 165(1):245-248

Guimaraes S, Moura D (2001) Vascular adrenoceptors: an update. Pharmacol Rev 53(3):319-356

Gupta A, Gupta S, Pavuk M, Roehrborn CG (2006) Anthropometric and metabolic factors and risk of benign prostatic hyperplasia: a prospective cohort study of Air Force veterans. Urology 68(6):1198-1205

Hashitani H, Mitsui R, Shimizu Y, Higashi R, Nakamura K (2012) Functional and morphological properties of pericytes in suburothelial venules of the mouse bladder. Br J Pharmacol 167(8):1723-1736

Inoue S, Saito M, Tsounapi P, Dimitriadis F, Ohmasa F, Kinoshita Y, Satoh K, Takenaka A (2012) Effect of silodosin on detrusor overactivity in the male spontaneously hypertensive rat. BJU Int 110(2 Pt 2):E118-E124

Ishida T, Shimoda N, Sato K, Ogawa O, Nishizawa O, Kato T (1999) Effects of ischemia on voiding function and nerve growth factor on the rat urinary bladder. Nippon Hinyokika Gakkai Zasshi 90(5): 564-571

Kershen RT, Azadzoi KM, Siroky MB (2002) Blood flow, pressure and compliance in the male human bladder. J Urol 168(1):121-125

Kirby MG, Wagg A, Cardozo L, Chapple C, Castro-Diaz D, de Ridder D, Espuna-Pons M, Haab F, Kelleher C, Kölbl H, Milsom I, van Kerrebroeck P, Vierhout M, Salvatore S, Tubaro A (2010) Overactive bladder: is there a link to the metabolic syndrome in men? Neurourol Urodyn 29(8):1360-1364

Kirpatovskii VI, Mudraya IS, Mkrtchyan KG, Revenko SV, Efremov GD, Nadtochii ON, Kabanova IV (2015) Ischemia in pelvic organs as an independent pathogenic factor in the development of benign prostatic hyperplasia and urinary bladder dysfunction. Bull Exp Biol Med 158(6):718-722

Koritsiadis G, Stravodimos K, Koutatellis G, Agrogiannis G, Koritsiadis S, Lazaris A, Constantinides C (2008) Immunohistochemical estimation of hypoxia in human obstructed bladder and correlation with clinical variables. BJU Int 102(3):28-332

Kupelian V, McVary KT, Kaplan SA, Hall SA, Link CL, Aiyer LP, Mollon P, Tamimi N, Rosen RC, McKinlay JB (2009) Association of lower urinary tract symptoms and the metabolic syndrome: results from the Boston Area Community Health Survey. J Urol 182(2): 616-625

Lee W-C, Chien C-T, Yu H-J, Lee S-W (2008) Bladder dysfunction in rats with metabolic syndrome induced by long-term fructose feeding. J Urol 179(6):2470-2476

Levin RM, English M, Barretto M, Dubuc M, O'Connor L, Leggett R, Whitbeck C (2000) Normal detrusor is more sensitive than hypertrophied detrusor to in vitro ischemia followed by re-oxygenation. Neurourol Urodyn 19(6):701-712

Lin W-Y, Mannikarottu A, Li S, Juan Y-S, Schuler C, Javed Z, Blaivas J, Levin RM (2011) Correlation of in vivo bladder flow measurements with tissue hypoxia. World J Urol 29(2):165-170

Liu H, Liu P, Mao G, Chen G, Wang B, Qin X, Na Y, Liu Z, Wang X, Xu $X$ (2009) Efficacy of combined amlodipine/terazosin therapy in male hypertensive patients with lower urinary tract symptoms: a randomized, double-blind clinical trial. Urology 74(1):130-136

Martin SA, Haren MT, Marshall VR, Lange K, Wittert GA (2011) Prevalence and factors associated with uncomplicated storage and voiding lower urinary tract symptoms in community-dwelling Australian men. World J Urol 29(2):179-184

Martin S, Lange K, Haren MT, Taylor AW, Wittert G (2014) Risk factors for progression or improvement of lower urinary tract symptoms in a prospective cohort of men. J Urol 191(1):130-137

McVary KT, Rademaker A, Lloyd GL, Gann P (2005) Autonomic nervous system overactivity in men with lower urinary tract symptoms secondary to benign prostatic hyperplasia. J Urol 174(4):1327-1333

Michel MC (2014) Do b-adrenoceptor agonists induce homologous or heterologous desensitization in rat urinary bladder? Naunyn Schmiedeberg's Arch Pharmacol 387(3):215-224

Michel MC (2015) Therapeutic modulation of urinary bladder function: multiple targets at multiple levels. Anuual Rev Pharmacol Toxicol 55:269-287

Michel MC, Barendrecht MM (2008) Physiological and pathological regulation of the autonomic control of urinary bladder contractility. Pharmacol Ther 117:297-312

Michel MC, Igawa Y (2015) Therapeutic targets for overactive bladder other than smooth muscle. Expert Opin Ther Targets 19(5):687-705

Michel MC, Mehlburger L, Schumacher H, Bressel H-U, Goepel M (2000) Effect of diabetes on lower urinary tract symptoms in patients with benign prostatic hyperplasia. J Urol 163(6):1725-1729

Michel MC, Heemann U, Schumacher H, Mehlburger L, Goepel M (2004) Association of hypertension with symptoms of benign prostatic hyperplasia. J Urol 172(4):1390-1393

Mine S, Yamamoto T, Mizuno H, Endo K, Matsukawa Y, Funahashi Y, Kato M, Hattori R, Gotoh M (2013) Effect of tamsulosin on bladder microcirculation in rat model of bladder outlet obstruction using pencil lens charge-coupled device microscopy system. Urology 81(1):155-159

Mitterberger M, Pallwein L, Gradl J, Frauscher F, Neuwirt H, Leunhartsberger N, Strasser H, Bartsch G, Pinggera GM (2007) Persistent detrusor overactivity after transurethral resection of the prostate is associated with reduced perfusion of the urinary bladder. BJU Int 99(4):831-835

Mizuno H, Yamamoto T, Okutsu H, Ohtake A, Sasamata M, Matsukawa Y, Funahashi Y, Kato M, Hattori R, Gotoh M (2010) Microcirculation in a rat ischemia-reperfusion model, evaluated by pencil lens charge-coupled device microscopy system. Urology 76(1266.e1):1266.e5

Nomiya M, Sagawa K, Yazaki J, Takahashi N, Kushida N, Haga N, Aikawa K, Matsui T, Oka M, Fukui T, Andersson K-E, Yamaguchi $\mathrm{O}$ (2012a) Increased bladder activity is associated with elevated oxidative stress markers and proinflammatory cytokines in a rat model of atherosclerosis-induced chronic bladder ischemia. Neurourol Urodyn 31(1):185-189

Nomiya M, Yamaguchi O, Andersson K-E, Sagawa K, Aikawa K, Shishido K, Yanagida T, Kushida N, Yazaki J, Takahashi N (2012b) The effect of atherosclerosis-induced chronic bladder ischemia on bladder function in the rat. Neurourol Urodyn 31(1):195-200

Nomiya M, Yamaguchi O, Akaihata H, Hata J, Sawada N, Kojima Y, Andersson K-E (2014) Progressive vascular damage may lead to bladder underactivity in rats. J Urol 191(5):1462-1469

Ochodnicky P, Cruz CD, Yoshimura N, Michel MC (2011) Nerve growth factor in bladder dysfunction: contributing factor, biomarker and therapeutic target. Neurourol Urodyn 30:1227-1241

Okutsu H, Matsumoto S, Hanai T, Noguchi Y, Fujiyasu N, Ohtake A, Suzuki M, Sato S, Sasamata M, Uemura H, Kurita T (2010) Effects of tamsulosin on bladder blood flow and bladder function in rats with bladder outlet obstruction. Urology 75(1):235-240

Okutsu H, Mastumoto S, Ohtake A, Suzuki M, Sato S, Sasamata M, Uemura H (2011) Effect of tamsulosin on bladder blood flow and 
bladder function in a rat model of bladder over distention/emptying induced bladder overactivity. J Urol 186(6):2470-2477

Parsons JK, Messer K, White M, Barrett-Connor E, Bauer DC, Marshall LM (2011) Obesity increases and physical activity decreases lower urinary tract symptom risk in older men: the Osteoporotic Fractures in Men study. Eur Urol 60(6):1173-1180

Parsons BA, Drake MJ, Gammie A, Fry CH, Vahabi B (2012) The validation of a functional, isolated pig bladder model for physiological experimentation. Front Pharmacol 3:52

Peters SLM, Schmidt M, Michel MC (2006) Rho kinase: a target for treating urinary bladder dysfunction? Trends Pharmacol Sci 27(9):492-497

Ponholzer A, Temml C, Wehrberger C, Marszalek M, Madersbacher S (2006) The association between vascular risk factors and lower urinary tract symptoms in both sexes. Eur Urol 50(3):581-586

Pontari MA, Ruggieri MR (1999) Sex differences and role of nitric oxide in blood flow of canine urinary bladder. Am J Physiol 276(2 Pt 2): R407-R413

Rajasekaran M, Wilkes N, Kuntz S, Albo ME (2005) Rho-kinase inhibition suppresses bladder hyperreactivity in spontaneously hypertensive rats. Neurourol Urodyn 24(3):295-300

Recio P, Orensanz LM, Martinez MP, Navarro-Dorado J, Bustamente S, Garcia-Sacristan A, Prieto D, Hernandez M (2008) Noradrenergic vasoconstriction of pig prostatic small arteries. Naunyn Schmiedeberg's Arch Pharmacol 376(6):397-406

Rohrmann S, Smit E, Giovannucci E, Platz EA (2005) Association between markers of the metabolic syndrome and lower urinary tract symptoms in the Third National Health and Nutrition Examination Survey (NHANES III). Int J Obesity 29(3):310-316

Rudner XL, Berkowitz BA, Booth JV, Funk BL, Cozart KL, D'Amico EB, El-Moalem H, Page SO, Richardson CD, Winters B, Marucci L, Schwinn DA (1999) Subtype specific regulation of human vascular $\mathrm{a}_{1}$-adrenergic receptors by vessel bed and age. Circulation 100 : 2336-2343

Saito M, Tsounapi P, Oikawa R, Shimizu S, Honda M, Sejima T, Kinoshita Y, Tomita S (2014) Prostatic ischemia induces ventral prostatic hyperplasia in the SHR; possible mechanism of development of BPH. Sci Rep 4:3822
Shenfeld OZ, Meir KS, Yutkin V, Gofrit ON, Landau EH, Pode D (2005) Do atherosclerosis and chronic bladder ischemia really play a role in detrusor dysfunction of old age? Urology 65(1):181-184

Stewart WF, Minassian VA, Hirsch AG, Kolodner K, Fitzgerald M, Burgio K, Cundiff GW, Blaivas J, Newman D, Lerch VR, Dilley A (2010) Predictors of variability in urinary incontinence and overactive bladder symptoms. Neurourol Urodyn 29:328-335

Turner WH, Brading AF (1999) Smooth muscle of the bladder in the normal and the diseased state: pathophysiology, diagnosis and treatment. Pharmacol Ther 75(2):77-110

Vikram A, Jena G, Ramarao P (2010) Insulin-resistance and benign prostatic hyperplasia: the connection. Eur J Pharmacol, 75-81

Wada N, Matsumoto S, Kita M, Hashizume K, Kakizaki H (2015) Improvement of overactive bladder symptoms and bladder ischemia with dutasteride in patients with benign prostatic enlargement. LUTS 7(1):37-41

Witte LPW, de Haas N, Mammen M, Stangeland EL, Steinfeld T, Aiyar J, Michel MC (2011) Muscarinic receptor subtypes and signalling involved in the attenuation of isoprenaline-induced rat urinary bladder relaxation. Naunyn Schmiedeberg's Arch Pharmacol 384(6):555563

Yono M, Yamamoto Y, Yoshida M, Ueda S, Latifpour J (2007) Effects of doxazosin on blood flow and mRNA expression of nitric oxide synthase in the spontaneously hypertensive rat genitourinary tract. Life Sci 81(3):218-222

Yoshimura N, Miyazoto M, Kitta T, Yoshikawa S (2014a) Central nervous targets for the treatment of bladder dysfunction. Neurourol Urodyn 33(1):59-66

Yoshimura N, Obuchi T, Yokoyama H, Funahashi Y, Yoshikawa S, Sugino Y, Kawamorita N, Kashyap MP, Chancellor MB, Tyagi P, Ogawa T (2014b) Bladder afferent hyperexcitability in bladder pain syndrome/interstitial cystitis. Int J Urol 21(Suppl 1):18-25

Zhang X, Li G, Wei X, Mo X, Hu L, Zha Y, Hou J (2012) Resistive index of prostate capsular arteries: a newly identified parameter to diagnose and assess bladder outlet obstruction in patients with benign prostatic hyperplasia. J Urol 188(3):881-887 